\title{
PLAN ESTRATÉGICO DE MARKETING TERRITORIAL PARA EL MUNICIPIO DE PITALITO HUILA
}

\section{STRATEGIC TERRITORIAL MARKETING PLAN FOR THE MUNICIPALITY}

\section{OF PITALITO HUILA}

\section{Autor 1. Clara Sofía Caviedes Villegas}

Administradora de Empresas, UNAD, Especialista en Gerencia Estratégica de Mercadeo, Magister en Administración de Empresas de la UNAD Florida y Magister en Administración de Organizaciones UNAD. Docente Universidad Nacional Abierta y a Distancia UNAD Grupo de grupo de investigación: Cananguchales ORCID: https://orcid.org/0000-0001-7991-1699. Correo electrónico: clara.caviedes@unad.edu.co

\section{RESUMEN}

El estudio de prospectiva de marketing territorial se realizó en el Municipio de Pitalito Huila, que está ubicado geográficamente en una estrella vial donde convergen varios departamentos como Cauca, Caquetá, Putumayo, Nariño, convirtiéndolo en el epicentro comercial del sur de Colombia, este municipio se ha convertido en los últimos años como una región receptora de víctimas del conflicto armado que buscan nuevas y mejores oportunidades de vida, de acuerdo a este planteamiento y teniendo en cuenta el contexto del post acuerdo, se plantea la investigación utilizando una metodología prospectiva, con un análisis estructural que contempla el diseño de un escenario ideal para un territorio de paz. Para construir las estrategias para del Plan de Marketing Territorial, se aplica la teoría del mix marketing para ciudades identificado por diversos autores como las 4A que componen las Amenidades, Atractivos, Accesibilidad y la Acción de la Ciudad.

Subsiguientemente, se realiza la construcción de un Plan Estratégico, definiendo como elementos de marketing de territorio, identidad, imagen con el propósito de mostrar a Pitalito como un territorio con identidad propia y una marca diferenciadora, a través, de la exposición de los atributos, ubicación, contexto, capacidades y coherencia, y posicionar el Municipio de Pitalito como un territorio de paz el año 2030 con mejores oportunidades para la inversión empresarial en turismo y agronegocios.

Palabras clave: Marketing territorial; estrategias; prospectiva; posicionamiento, marca ciudad.

\section{ABSTRACT}

The territorial marketing prospective study was carried out in the Municipality of Pitalito Huila, which is geographically located in a road star where several departments such as Cauca, Caquetá, Putumayo, Nariño converge, making it the commercial epicenter of southern Colombia, this municipality is In recent years it has become a receiving region for victims of the armed conflict who are looking for new and better life opportunities, according to this approach and taking into account the context of the post agreement, the research is proposed using a prospective methodology, with a structural analysis that contemplates the design of an ideal scenario for a territory of peace. 

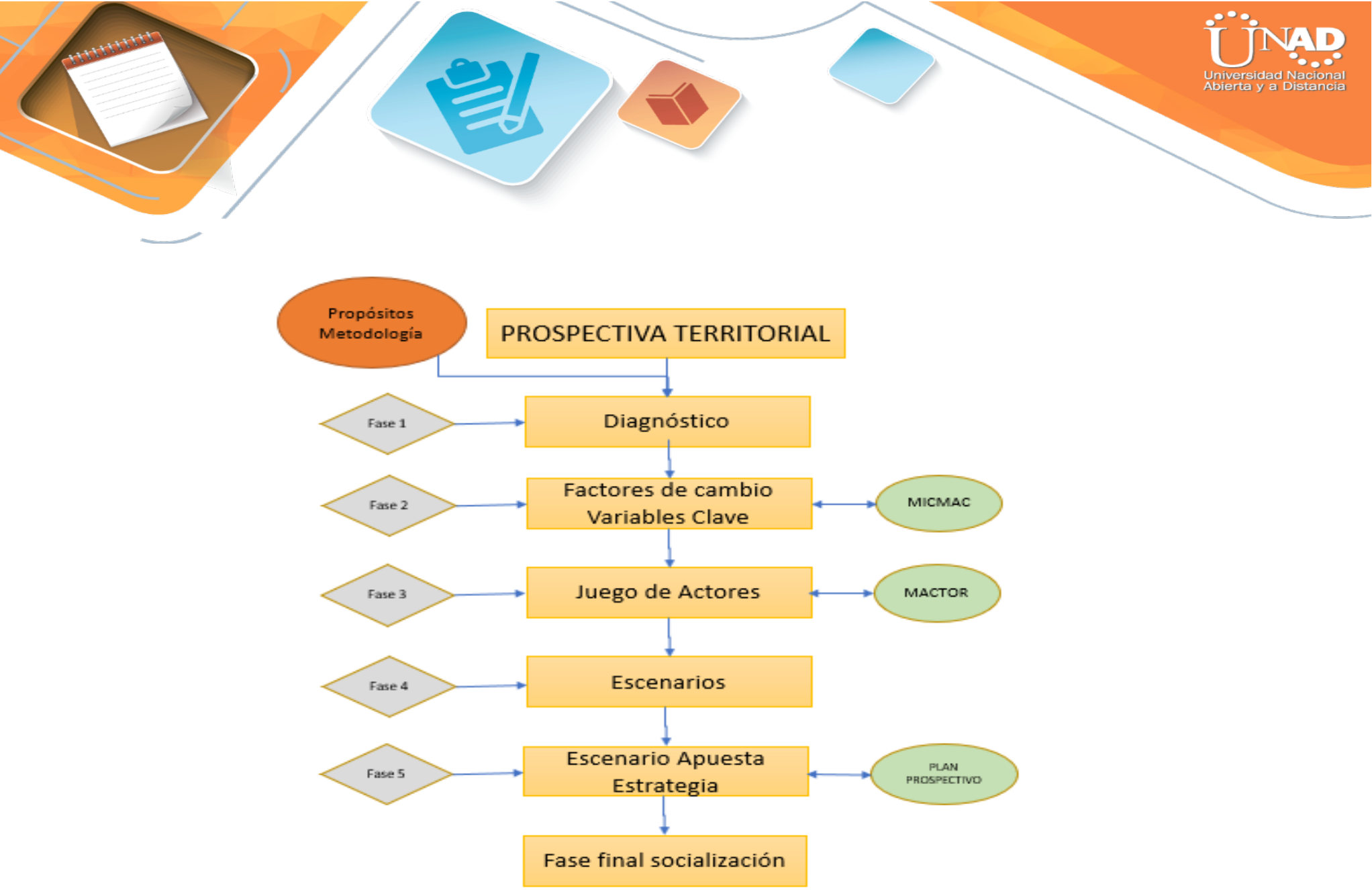

\section{DISCUSIÓN Y RESULTADOS}

Para la construcción del Plan Estratégico, se ha definido como elementos de marketing de territorio identidad, imagen y comunicación tiene como propósito general posicionar a Pitalito como un territorio de Paz a través de la exposición de los atributos diferenciadores del mismo. Para lo cual se definieron los siguientes objetivos:

\section{Objetivos propuestos}

Rescatar la identidad de Territorio de Paz de Pitalito a partir de la identificación de la vocación, el contexto, capacidades y coherencia, con el fin de lograr un posicionamiento a nivel nacional e internacional.

Diseñar la imagen de Territorio de Paz de Pitalito a partir de la percepción de los actores locales, proyectándolo a nivel nacional e internacional.

Diseñar una política de comunicación a partir de los cinco pilares que conlleve a una interrelación de actores internos y externos del territorio.

\section{Metas propuestas}

Posicionar el Municipio de Pitalito como un territorio de paz el año 2030 con mejores oportunidades para la inversión empresarial en turismo y agronegocios.

Incrementar en $50 \%$ el número de visitantes y turistas a los diferentes servicios ofrecidos por el territorio y los municipios aledaños.

Mejorar la competitividad económica del municipio en materia de infraestructura vial, de servicios públicos y conectividad digital.

\section{Marco estratégico}

Para construir las estrategias para del Plan de Marketing Territorial para el Municipio de Pitalito Huila, se aplica la metodología del mix marketing para ciudades identificado por 

concepto de identidad sobre el cual se desarrolle el sector turístico. (Ramírez Castrillón, 2015)

Coherencia. Para aprovechar al máximo las potencialidades que posee el municipio se requiere de múltiples sinergias para la promoción de agremiaciones privadas con los sectores público, privado y la academia. Una articulación de las 4A que componen las Amenidades, Atractivos, Accesibilidad y la Acción de la Ciudad, que componen el mix Citymarketing de Pitalito.

\section{Visión de Pitalito Huila}

En el año 2030 Pitalito será un territorio de paz digno de sus pobladores, una ciudad en donde los sueños de los laboyanos puedan ser realizables, mejoren las oportunidades para los niños, niñas y adolescentes procurando su desarrollo integral, donde los pobladores estemos preparados para recibir el desarrollo y progreso que nos consolidará como la capital del sur colombiano.

Estrategia Competitiva

Ofrecer productos diferenciados, en segmentos y mercaos especializados que permita aprovechar las fortalezas y características del territorio del Valle de Laboyos: Un destino cultural único donde se active la Ruta de los Sentidos.

\section{Plan estratégico de marketing territorial para el Municipio de} Pitalito Huila

\begin{tabular}{|c|c|c|c|c|}
\hline Metas & Estrategias & Acciones & Responsable & Tiempo \\
\hline \multirow[t]{2}{*}{$\begin{array}{l}\text { Posicionar el } \\
\text { Municipio de } \\
\text { Pitalito como un } \\
\text { territorio de paz } \\
\text { el año } 2030 \text { con } \\
\text { mejores } \\
\text { oportunidades } \\
\text { para la inversión } \\
\text { empresarial en } \\
\text { turismo y } \\
\text { agronegocios. }\end{array}$} & $\begin{array}{l}\text { Estrategia de } \\
\text { Identidad } \\
\text { Identificar cada uno } \\
\text { de los atributos } \\
\text { diferenciadores que } \\
\text { la hacen especial el } \\
\text { Valle de Laboyos, } \\
\text { entre los que se } \\
\text { cuentan la vocación, } \\
\text { el contexto, } \\
\text { capacidades y } \\
\text { coherencia. }\end{array}$ & $\begin{array}{l}\text { Construir un } \\
\text { portafolio de los } \\
\text { atributos del } \\
\text { territorio, } \\
\text { haciendo énfasis } \\
\text { en la vocación }\end{array}$ & $\begin{array}{l}\text { Alcaldía de } \\
\text { Pitalito } \\
\text { Empresas. } \\
\text { Descentralizadas } \\
\text { del Municipio. } \\
\text { Comité de } \\
\text { Cafeteros } \\
\text { Cámara de } \\
\text { Comercio de } \\
\text { Neiva - Seccional } \\
\text { Pitalito } \\
\text { Universidades - } \\
\text { SENA }\end{array}$ & 36 meses \\
\hline & $\begin{array}{l}\text { Estrategia de } \\
\text { Imagen } \\
\text { Es la forma de como } \\
\text { los actores locales } \\
\text { pretenden que el } \\
\text { territorio sea } \\
\text { percibido, para lo } \\
\text { cual se la definido la } \\
\text { Ruta de los Sentidos. } \\
\text { Tacto: Arcilla } \\
\text { Olfato: Guayaba y } \\
\text { café } \\
\text { Vista: Orquideas y } \\
\text { paisajes y pintores } \\
\text { Gusto: Proceso del }\end{array}$ & $\begin{array}{l}\text { Gestionar } \\
\text { recursos del } \\
\text { estado para el } \\
\text { apoyo a las } \\
\text { diferentes ferias } \\
\text { y eventos que } \\
\text { potencializan la } \\
\text { ruta de los } \\
\text { sentidos. }\end{array}$ & $\begin{array}{l}\text { Alcaldía de } \\
\text { Pitalito } \\
\text { Empresas. } \\
\text { Comité de } \\
\text { Cafeteros } \\
\text { Cámara de } \\
\text { Comercio de } \\
\text { Neiva - Seccional } \\
\text { Pitalito } \\
\text { Universidades - } \\
\text { SENA }\end{array}$ & 36 meses \\
\hline
\end{tabular}




\begin{tabular}{|c|c|c|c|c|}
\hline \multirow[t]{3}{*}{ Metas } & Estrategias & Acciones & Responsable & Tiempo \\
\hline & $\begin{array}{l}\text { Café, degustación y } \\
\text { catación. }\end{array}$ & & & \\
\hline & $\begin{array}{l}\text { Estrategia de } \\
\text { Comunicación } \\
\text { Articular la } \\
\text { comunicación } \\
\text { específica de } \\
\text { productos definidos } \\
\text { en las 4A, a través } \\
\text { de campañas que } \\
\text { intentan sintetizar en } \\
\text { piezas de } \\
\text { comunicación la } \\
\text { propuesta de valor } \\
\text { de los productos. }\end{array}$ & $\begin{array}{l}\text { Construir una } \\
\text { comunicación } \\
\text { hacia actores } \\
\text { externos al } \\
\text { territorio } \\
\text { Marketing } \\
\text { externo } \\
\text { Desarrollar } \\
\text { atención sobre } \\
\text { las } \\
\text { potencialidades } \\
\text { del territorio } \\
\text { Evidenciar el } \\
\text { posicionamiento } \\
\text { competitivo } \\
\text { territorial } \\
\text { Brindar } \\
\text { informaciones } \\
\text { sobre la } \\
\text { estrategia y los } \\
\text { proyectos de } \\
\text { desarrollo } \\
\text { Favorecer las } \\
\text { relaciones con } \\
\text { actores locales. } \\
\text { Construir una } \\
\text { comunicación } \\
\text { hacia actores } \\
\text { internos al } \\
\text { territorio } \\
\text { Marketing } \\
\text { interno }\end{array}$ & $\begin{array}{l}\text { Alcaldía de } \\
\text { Pitalito } \\
\text { Cámara de } \\
\text { Comercio de } \\
\text { Neiva - Seccional } \\
\text { Pitalito }\end{array}$ & 60 meses \\
\hline $\begin{array}{l}\text { Incrementar en } \\
50 \% \text { el número } \\
\text { de visitantes y } \\
\text { turistas a los } \\
\text { diferentes } \\
\text { servicios } \\
\text { ofrecidos por el } \\
\text { territorio y los } \\
\text { municipios } \\
\text { aledaños. }\end{array}$ & $\begin{array}{l}\text { Realizar alianzas } \\
\text { estratégicas con el } \\
\text { Parque Arqueológico } \\
\text { de San Agustín e } \\
\text { Isnos, con el fin de } \\
\text { prestar los servicios } \\
\text { hoteleros y de } \\
\text { restaurantes en } \\
\text { Pitalito. } \\
\text { Articular con las } \\
\text { agencias de viajes }\end{array}$ & $\begin{array}{l}\text { Gestionar } \\
\text { recursos del } \\
\text { estado para el } \\
\text { apoyo a las } \\
\text { diferentes ferias } \\
\text { y eventos que } \\
\text { potencializan la } \\
\text { ruta de los } \\
\text { sentidos. } \\
\text { Diseñar el } \\
\text { portafolio de la }\end{array}$ & $\begin{array}{l}\text { Alcaldía de } \\
\text { Pitalito } \\
\text { Cámara de } \\
\text { Comercio de } \\
\text { Neiva - Seccional } \\
\text { Pitalito }\end{array}$ & 48 meses \\
\hline
\end{tabular}




\begin{tabular}{|c|c|c|c|c|}
\hline Metas & Estrategias & Acciones & Responsable & Tiempo \\
\hline & $\begin{array}{l}\text { las fiestas y eventos } \\
\text { que se realizan en } \\
\text { Pitalito. }\end{array}$ & $\begin{array}{l}\text { Ruta de los } \\
\text { Sentidos del } \\
\text { territorio de Paz. }\end{array}$ & & \\
\hline $\begin{array}{l}\text { Mejorar la } \\
\text { competitividad } \\
\text { económica del } \\
\text { municipio en } \\
\text { materia de } \\
\text { infraestructura } \\
\text { vial, de servicios } \\
\text { públicos y } \\
\text { conectividad } \\
\text { digital. }\end{array}$ & $\begin{array}{l}\text { Apoyar la } \\
\text { asociatividad en los } \\
\text { sectores } \\
\text { agropecuarios y } \\
\text { turísticos } \\
\text { Impulsar la } \\
\text { innovación y la } \\
\text { transformación de } \\
\text { las empresas } \\
\text { orientándolas hacia } \\
\text { la sostenibilidad. } \\
\text { Aprovechar la } \\
\text { potencialidad de } \\
\text { recursos naturales } \\
\text { para generar } \\
\text { negocios } \\
\text { sustentables. } \\
\text { Generar valor } \\
\text { agregado en las } \\
\text { empresas } \\
\text { aumentando su } \\
\text { cadena de valor. } \\
\text { Construir una } \\
\text { institucionalidad que } \\
\text { facilite el diálogo } \\
\text { público-privado. } \\
\text { Gobiernos } \\
\text { Municipales } \\
\text { fiscalmente } \\
\text { responsables e } \\
\text { inclusivos. }\end{array}$ & $\begin{array}{l}\text { Reconocer las } \\
\text { experiencias } \\
\text { exitosas } \\
\text { alrededor del } \\
\text { posconflicto en el } \\
\text { Territorio. } \\
\text { Diseñar } \\
\text { programas en } \\
\text { torno a los } \\
\text { Acuerdos de Paz. } \\
\text { Diseñar } \\
\text { programas de } \\
\text { educación } \\
\text { armónica en } \\
\text { torno a la paz } \\
\text { desde la Inicial } \\
\text { hasta la Superior } \\
\text { Mejoramiento } \\
\text { vial del territorio } \\
\text { Realizar acciones } \\
\text { en torno a la } \\
\text { resiliencia para } \\
\text { la acogida de los } \\
\text { actores del } \\
\text { conflicto }\end{array}$ & $\begin{array}{l}\text { Alcaldía de } \\
\text { Pitalito } \\
\text { Empresas. } \\
\text { Comité de } \\
\text { Cafeteros } \\
\text { Cámara de } \\
\text { Comercio de } \\
\text { Neiva - Seccional } \\
\text { Pitalito } \\
\text { Universidades - } \\
\text { SENA }\end{array}$ & 60 meses \\
\hline
\end{tabular}

Fuente: elaboración propia

\section{CONCLUSIONES}

El desarrollo de la investigación de marketing territorial en el Municipio de Pitalito, con metodología prospectiva, permitió el diseño de estrategias, partiendo de la revisión de los contextos económicos, productivos, ambientales, socio culturales e institucionales, donde se logró identificar las perspectivas de cambio y factores de éxito del Municipio. 
Martin Silva, P. (Dir.). (2015). Ruta de los Sentidos. [Película].

Mendez Alvarez, C. E. (2001). Metodología : guía para elaborar diseños de investigación en ciencias económicas, contables y administrativas. Bogotá, Colombia: McGraw-Hill.

Morad, G. E. (2018). Los colores y sabores de Pitalito. Recuperado de https://www.radionacional.co/noticia/marcha-pitalito/los-colores-sabores-de-pitalito

Municipio de Pitalito. (2016). Plan de Desarrollo Municipal. Pitalito. Recuperado de http://www.alcaldiapitalito.gov.co/normatividadvigente/Acuerdo_022-2016.pdf

Pitalito Noticias. (2016). En Imagenes: Festival Cultural Por La Paz En Pitalito Huila. Obtenido de http://www.pitalitonoticias.com/2016/07/festival-cultural-por-la-paz-en.html

Ramírez Castrillón, C. A. (2015). Perfil Productivo Municipio de Pitalito. Pitalito. Recuperado de https://ormethuiladotorg.files.wordpress.com/2015/12/perfil-productivo-municipio-depitalito.pdf 